\title{
Redescription of a Poorly Known Stingray, Dasyatis laevigata (Chondrichthyes: Dasyatidae), with Notes on Some Biological Aspects in Ariake Sea, Japan
}

\author{
Keisuke Furumitsu ${ }^{1}$, Jie Zhang ${ }^{2}$ and Atsuko Yamaguchi ${ }^{1}$ \\ ${ }^{1}$ Faculty of Fisheries, Nagasaki University, 1-14 Bunkyo, Nagasaki, 852-8521 Japan \\ E-mail: furusuke@nagasaki-u.ac.jp (KF); y-atsuko@nagasaki-u.ac.jp (AY) \\ ${ }^{2}$ Key Laboratory of Zoological Systematics and Evolution, Institute of Zoology, Chinese Acad- \\ emy of Sciences. No. 1 Beichen West Road, Chaoyang District, Beijing, 100101 China \\ E-mail: zhangjie@ioz.ac.cn
}

(Received 3 October 2008; Accepted 5 October 2010)

\begin{abstract}
The poorly known dasyatid stingray Dasyatis laevigata Chu, 1960 is redescribed on the basis of a single syntype and 18 recently collected specimens from Ariake Sea, Japan, and the East China Sea. Sexual dimorphism and growth-related variation in taxonomic characters are considered, and life history characteristics, such as distribution and size at maturity, are clarified on the basis of an additional 464 specimens.
\end{abstract}

Key Words: Dasyatidae, Yantai Stingray, Dasyatis laevigata, redescription, size at maturity.

\section{Introduction}

Dasyatis Rafinesque, 1810, one of seven genera of stingrays belonging to the family Dasyatidae, is characterized by a long, whip-like tail, a tail spine, and a ventral tail fold that terminates before the tail tip. The genus includes approximately 36 species (Gomes et al. 2000; Compagno 2005; Last and White 2008a, b; Last and Stevens 2009), eight of which are distributed in Japanese waters (Aonuma and Yoshino 2000).

Dasyatis laevigata Chu, 1960 was described on the basis of six specimens obtained from the Shanghai Fish Market, Dongfushan, and Huaniao, China. The first Japanese record of $D$. laevigata, from Tachibana Bay, Nagasaki Pref., was reported by Yamada and Irie (1989), but no morphological details were given. Subsequently, Furumitsu et al. (2006) noted that D. laevigata is also distributed in Ariake Sea, Japan, having long been misidentified there as D. akajei (Müller and Henle, 1841) owing to the morphological similarity of the two species. In fact, Nishida and Nakaya (1990) had earlier noted the potential for confused identifications within Dasyatis, owing to individual, sexual, and ontogenetic variation. Within recent years, many specimens of both $D$. laevigata and $D$. akajei have been collected in coastal areas off western Kyushu, Japan.

Chu (1960) did not indicate the repository of his syntypes, but one of the numbered specimens (154,103-8 (4)) was found in 2006 in the East China Sea Fisheries Research Institute of the Chinese Academy of Fishery Sciences in Shanghai. This specimen has subsequently gone missing there (see Remarks), and as the remain- 
ing five syntypes could not be traced at all, we assume they have been lost. Based on the temporarily located syntype and the other specimens examined in this study, D. laevigata is redescribed herein, with special attention paid to individual, sexual, and ontogenetic variation. Biological data on the distribution and size at maturity of $D$. laevigata are also presented, and comparisons are made with related western North Pacific dasyatid species.

\section{Material and Methods}

Methods and terminology for counts and measurements follow Compagno and Roberts $(1982,1984)$ and Nishida and Nakaya (1988a), except for the following: preventral tail fold length-distance from snout tip to anteriormost point of ventral tail fold; amphioral snout length-distance from snout tip to posteriormost point of mouth; pectoral fin anterior margin-distance from snout tip to outermost margin of disc; pectoral fin posterior margin-distance from posteriormost point of disc to outermost margin of disc. Disc width (DW) is considered as the standard measure of size in this study. Counts of radial cartilages and vertebrae, as well as observations of the pelvic girdle, were made using soft X-rays, following Compagno and Roberts (1982) and Nishida (1990). Unstained clasper skeletons were observed after flesh removal following Taniuchi and Ishihara (1990). Snout angle measurement and tooth counts follow Stehmann (1981). Pelvic girdle terminology and clasper terminology follow Nishida (1990) and Taniuchi and Ishihara (1990), respectively. Tooth rows, intestinal spiral valve turns, radial cartilages, and vertebrae of the female syntype were not counted before the specimen was misplaced, nor could the pelvic girdle be examined. In addition to this syntype, 18 specimens collected off western Kyushu, Japan, were used to redescribe D. laevigata. These 18 specimens were deposited in the National Museum of Nature and Science, Tokyo (NSMT). An additional 464 unregistered specimens (collected from Ariake Sea, Amakusa Sea, and Nomozaki, western Kyushu, Japan during 2003-2008) used for the "Biological Data" section, including estimation of size at sexual maturity and documentation of variation in the ratio of clasper length to DW and other morphological and morphometric characters, were later discarded. Maturity stages were assigned according to the degree of development of the testes and claspers in males, and ovaries and uteri in females, following Braccini and Chiaramonte (2002), as follows. Males: 1) immature, testes and claspers undeveloped; 2) sub-adult, testes becoming lobular, vas deferens beginning to thicken and coil, clasper elongated and flexible, not calcified; and 3) mature, testes and seminal vesicle fully developed, vas deferens fully developed and coiled, sperm may be present, claspers calcified. Females: 1) immature, ovary comprising white, undifferentiated tissue, uterus thin; 2) subadult, ovary carrying small, immature, opaque oocytes, uterus becoming thickened; and 3) mature, ovary containing ova with yolk, uterus fully developed and possibly with eggs or embryos.

Comparative specimens. Dasyatis akajei: NSMT-P 91833-91854. Dasyatis izuensis: NSMT-P 91829-91832. 


\section{Taxonomic Account}

Dasyatis laevigata Chu, 1960

[English name: Yantai Stingray Japanese name: Shiro-ei]

(Figs 1-5)

Dasyatis laevigatus Chu, 1960: 170-172, figs 160-162 (purchased at the Shanghai Fish Market, Dongfushan, and Huaniao, China); Chu et al. 1963: 65-66, fig. 52 (northern part of the East China Sea, the Shanghai Fish Market, Wenzhou Waihai, Shitang, and Sansha, China); Yamada and Irie 1989: 24 (Tachibana Bay, Nagasaki Pref., Japan); Nishida and Nakaya 1990: 341-342 (followed Chu (1960)); Chen and Joung 1993: 85 (Taiwan); Aonuma and Yoshino 2000: 182; Zhu and Meng, 2001: 420-422, fig. 220 (followed Chu (1960)).

Dasyatis laevigata: Furumitsu et al. 2006: 32-34, figs 1, 2, 4; Furumitsu 2009: 25-28, fig. 14.

Specimens examined. Syntype: 154,103-8 (4) (Fig. 1) (formerly deposited in the East China Sea Fisheries Research Institute of the Chinese Academy of Fishery Sciences in Shanghai, examined in April 2006, but lost in December 2009), female, immature, $446 \mathrm{~mm}$ TL, $205 \mathrm{~mm}$ DW, Huaniao, China, 2 June 1956.

Comparative non-type specimens (all from Japan): NSMT-P 91808, immature male, $221 \mathrm{~mm}$ DW, off Mogi, Tachibana Bay, Nagasaki Pref., 8 February 1967; 91809, mature female, $292 \mathrm{~mm}$ DW, off Tara, Ariake Sea, Saga Pref., 28 June 2004; 91810, mature male, $237 \mathrm{~mm}$ DW, same as 91809; 91811, immature female, $128 \mathrm{~mm}$ DW, East China Sea, off Nomozaki, Nagasaki Pref., 16 July 2004; 91812, immature male, $124 \mathrm{~mm}$ DW, same as 91811; 91813 (Fig. 2A, B), mature male, $225 \mathrm{~mm} \mathrm{DW}$, off Shimabara, Ariake Sea, Nagasaki Pref., 3 May 2005; 91814, sub-adult male, $203 \mathrm{~mm}$ DW, same as 91813, 24 September 2005; 91816, immature male, $177 \mathrm{~mm}$ DW, same as 91813, 16 November 2005; 91817, immature female, $260 \mathrm{~mm}$ DW, off Higashi-yoka, Ariake Sea, Saga Pref., 12 May 2006; 91818 (Fig. 2C, D), mature female, $303 \mathrm{~mm}$ DW, same as 91817 ; 91819, immature female, $264 \mathrm{~mm}$ DW, same as 91817 ; 91820 , sub-adult
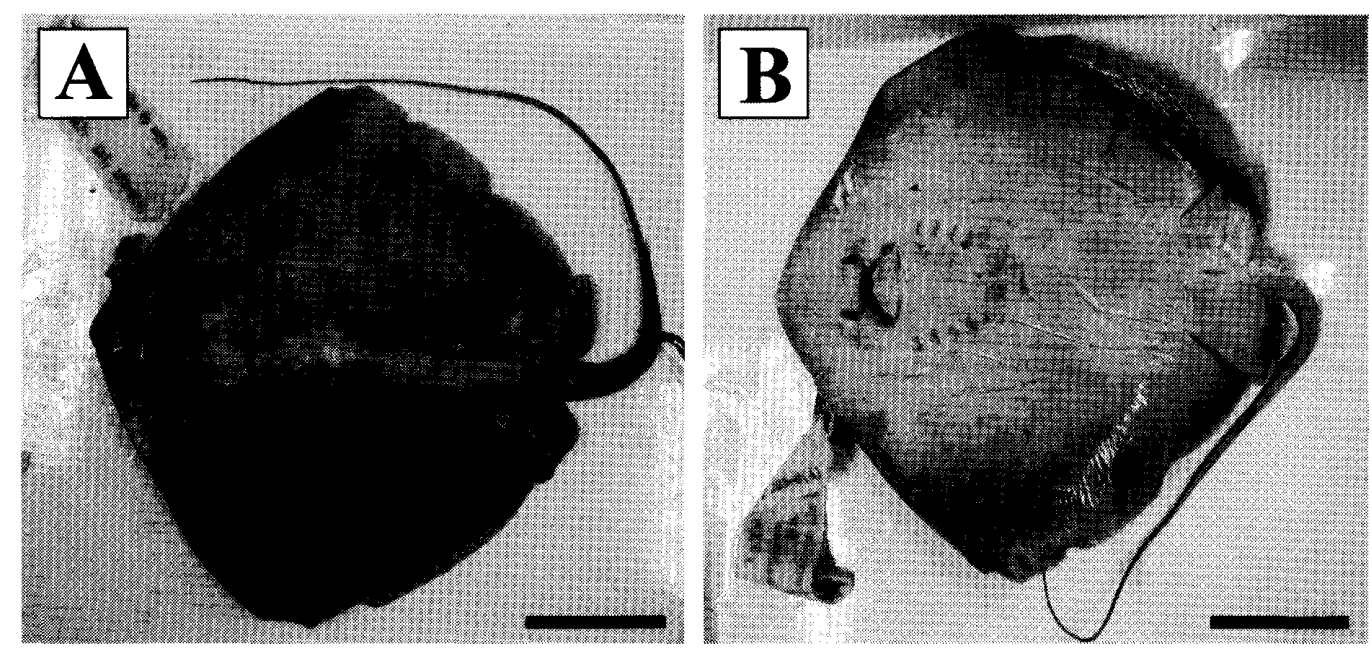

Fig. 1. Dasyatis laevigata, syntype, $205 \mathrm{~mm}$ DW, immature female, 154,103-8 (4). A, Dorsal view; B, ventral view. Scale bars: $50 \mathrm{~mm}$. 

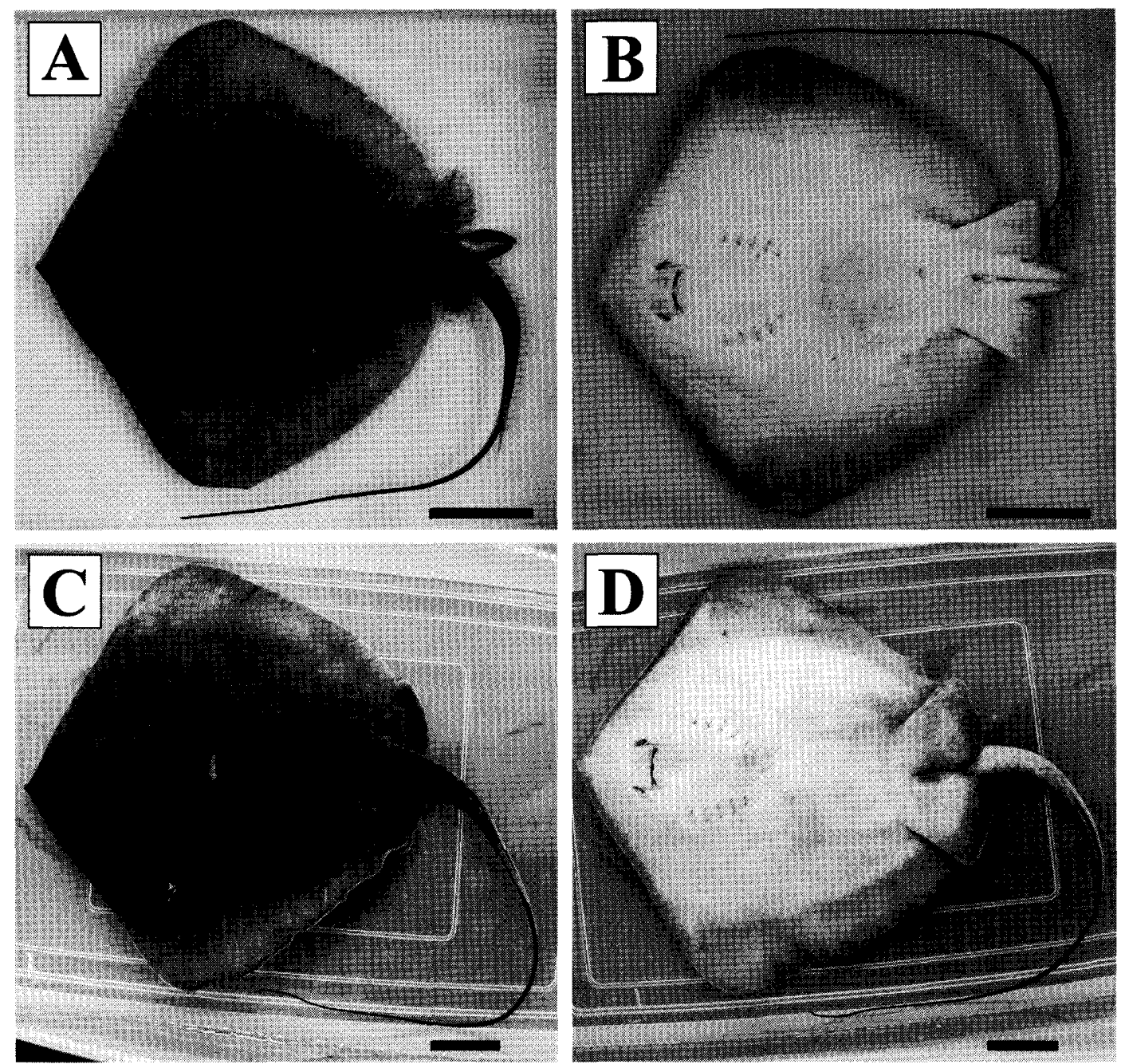

Fig. 2. Dasyatis laevigata. A, B, NSMT-P 91813, $225 \mathrm{~mm}$ DW, mature male; C, D, NSMT-P 91818, $303 \mathrm{~mm}$ DW, mature female. Scale bars: $50 \mathrm{~mm}$.

male, $224 \mathrm{~mm}$ DW, same as 91817 ; 91821, mature male, $226 \mathrm{~mm}$ DW, same as 91817 ; 91822, immature male, $120 \mathrm{~mm}$ DW, same as 91817 , 13 July 2006; 91823, immature female, $250 \mathrm{~mm}$ DW, Amakusa Sea, off Ushibuka, Kumamoto Pref., 17 January 2007; 91824, sub-adult male, $246 \mathrm{~mm} \mathrm{DW}$, same as 91823 ; 93294, mature female, $321 \mathrm{~mm}$ DW, off Shimabara, Ariake Sea, Nagasaki Pref., 23 April 2002; and 96557, mature female, $296 \mathrm{~mm}$ DW, same as 93294, 17 July 2009.

Diagnosis. This species is distinguished from its congeners by the following combination of characters: disc rhomboid, width $111.5-123.5 \%$ of length; snout broadly triangular, angle $108-120^{\circ}$, preorbital length $138.3-182.6 \%$ of interorbital width; amphioral length $225.0-288.6 \%$ of mouth width; internasal distance $51.7-69.6 \%$ of prenasal length; body and tail mostly naked; dorsal surface of disc usually naked, sometimes with single row of up to 3 thorns along midline of disc; tail relatively long, slender, whip-like beyond posteriormost spine, tail width $140.5-192.9 \%$ of its depth, tail length $135.6-227.1 \%$ of precloacal length; ventral tail fold long, slender, its length $35.2-62.1 \%$ of $\mathrm{DW}$; preventral tail fold short, $105.0-116.8 \%$ of DW; dorsal tail fold elongate, low, much shorter than ventral tail 
fold; oral papillae 1-4 (mostly 3); intestinal spiral valve turns 16-18; total pectoral radials $98-103$; prespine separate centra $87-96$.

Description. Proportional measurements and counts of the syntype and other specimens are given in Tables 1 and 2, respectively. In the following description, measurements and counts are given for the syntype, with ranges for 18 additional specimens in parentheses.

Table 1. Proportional measurements (as \% of DW) of Dasyatis laevigata.

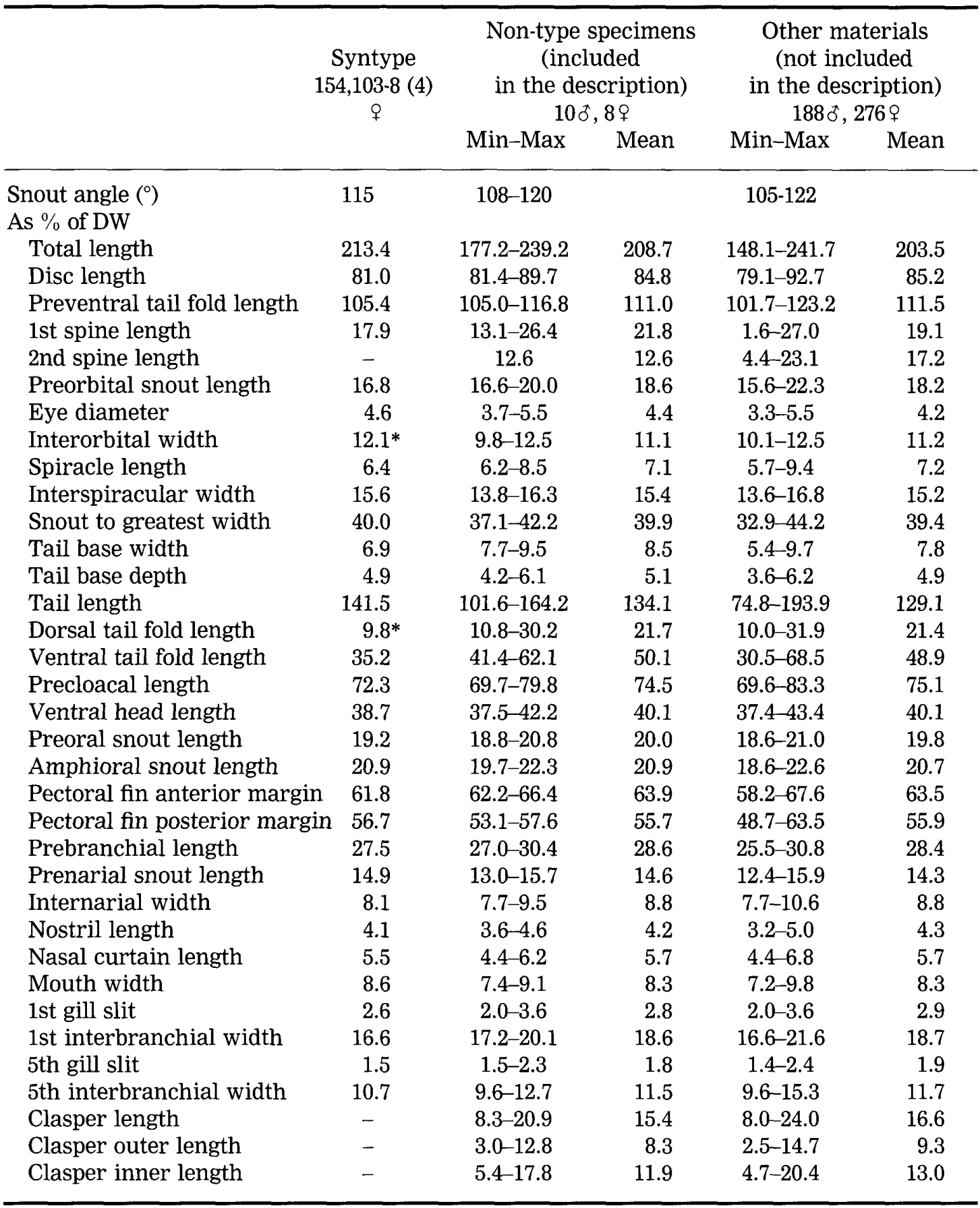

* Measurements from photo. 
Table 2. Counts for Dasyatis laevigata.

\begin{tabular}{|c|c|c|c|c|c|}
\hline & \multirow[t]{2}{*}{$\begin{array}{c}\text { Syntype } \\
154,103-8(4) \\
q\end{array}$} & \multicolumn{2}{|c|}{$\begin{array}{c}\text { Non-type specimens } \\
\text { (included } \\
\text { in the description) } \\
100,89\end{array}$} & \multicolumn{2}{|c|}{$\begin{array}{c}\text { Other materials } \\
\text { (not included } \\
\text { in the description) } \\
188 \delta^{*}, 2769\end{array}$} \\
\hline & & Min-Max & Mean & Min-Max & Mean \\
\hline Oral papillae & 3 & $1-4$ & 2.9 & $1-8$ & 3.0 \\
\hline Upper tooth rows & - & $34-49$ & 43.4 & $37-55$ & 43.6 \\
\hline Lower tooth rows & - & $35-54$ & 46.1 & $40-63$ & 47.7 \\
\hline Intestinal spiral valve turns & - & $16-18$ & 17.0 & $15-20$ & 17.7 \\
\hline Total pectoral radials & - & $98-103$ & 100.3 & $99-101$ & 100.6 \\
\hline Propterygial radials & - & $40-44$ & 41.9 & $41-43$ & 41.8 \\
\hline Mesopterygial radials & - & $11-16$ & 13.4 & $12-16$ & 13.9 \\
\hline Metapterygial radials & - & $44-47$ & 45.0 & $42-46$ & 44.9 \\
\hline Pelvic radials (male) & & $19-22$ & 21.0 & $19-20$ & 19.5 \\
\hline Pelvic radials (female) & - & $24-27$ & 26.0 & $24-26$ & 24.8 \\
\hline Prespine separate centra & - & $87-96$ & 91.7 & $90-98$ & 93.1 \\
\hline 1st synarcual free centra & - & $3-6$ & 4.1 & $4-6$ & 4.6 \\
\hline Intersynarcual centra & - & $1-4$ & 3.2 & $3-5$ & 3.8 \\
\hline 2nd synarcual + monospondylous & - & $26-32$ & 29.8 & $28-33$ & 29.9 \\
\hline Prespine diplospondylous & - & $49-59$ & 54.8 & $51-57$ & 55.0 \\
\hline Postspine diplospondylous & - & $3-14$ & 8.4 & $4-17$ & 10.4 \\
\hline
\end{tabular}

Disc rhomboid, width slightly broader than length, $123.5 \%(111.5-122.9 \%)$ of length; snout triangular, slightly projecting, angle $115^{\circ}\left(108-120^{\circ}\right)$; anterior margin slightly concave; posterior margin of disk slightly convex; outer angles of disc rounded; posterior angles slightly angular. Preorbital snout length $16.8 \%$ $(16.6-20.0 \%)$ of DW; eyes small, eyeball diameter $27.1 \%(19.6-29.8 \%)$ of preorbital snout length, $37.7 \%(31.4-49.1 \%)$ of interorbital width, and $70.7 \%(52.2-78.7 \%)$ of spiracle length; interspiracular width $92.8 \%(73.2-97.9 \%)$ of preorbital snout length.

Mouth weakly arched, width $41.1 \%(34.6-44.4 \%)$ of amphioral snout length; midline of lower jaw with prominent indentation; teeth pavement-like, in quincunx pattern with 34-49 rows in upper jaw and 35-54 in lower jaw in non-type specimens, sexually dimorphic, adult males with pointed teeth in both jaws, females and juvenile males with blunt teeth (Fig. 3A-D); floor of mouth with 3 (1-4) elongate oral papillae. Posterior margin of nasal curtain relatively straight, fringed; longitudinal medial groove absent; nasal curtain length $26.1 \%(21.9-31.2 \%)$ of amphioral snout length; internarial width $38.5 \%(38.0-46.8 \%)$ of amphioral snout length. Ventral head length (VHL) $38.7 \%(37.5-42.2 \%)$ of DW; amphioral snout length $54.1 \%(48.6-54.1 \%)$ of VHL; prebranchial length $71.2 \%(69.0-72.9 \%)$ of VHL.

Gill slits weakly S-shaped, each laterally forming weakly fringed lobe; length of first gill slit $170.5 \%(125.9-187.4 \%)$ of length of fifth gill slit, $29.8 \%(25.7-44.8 \%)$ of mouth width; distance between first gill slits $206.2 \%(196.1-224.4 \%)$ of internasal distance, $43.0 \%(43.9-49.4 \%)$ of VHL; distance between fifth gill slits $133.1 \%$ (116.2-145.7\%) of internasal distance, $27.8 \%(24.4-31.4 \%)$ of VHL.

Tail relatively long, whip-like, length $174.7 \%(120.2-199.0 \%)$ of disc length. Tail with 1 or 2 spines; 1st spine length $12.6 \%(8.0-22.5 \%)$ of tail length, 2nd spine absent 

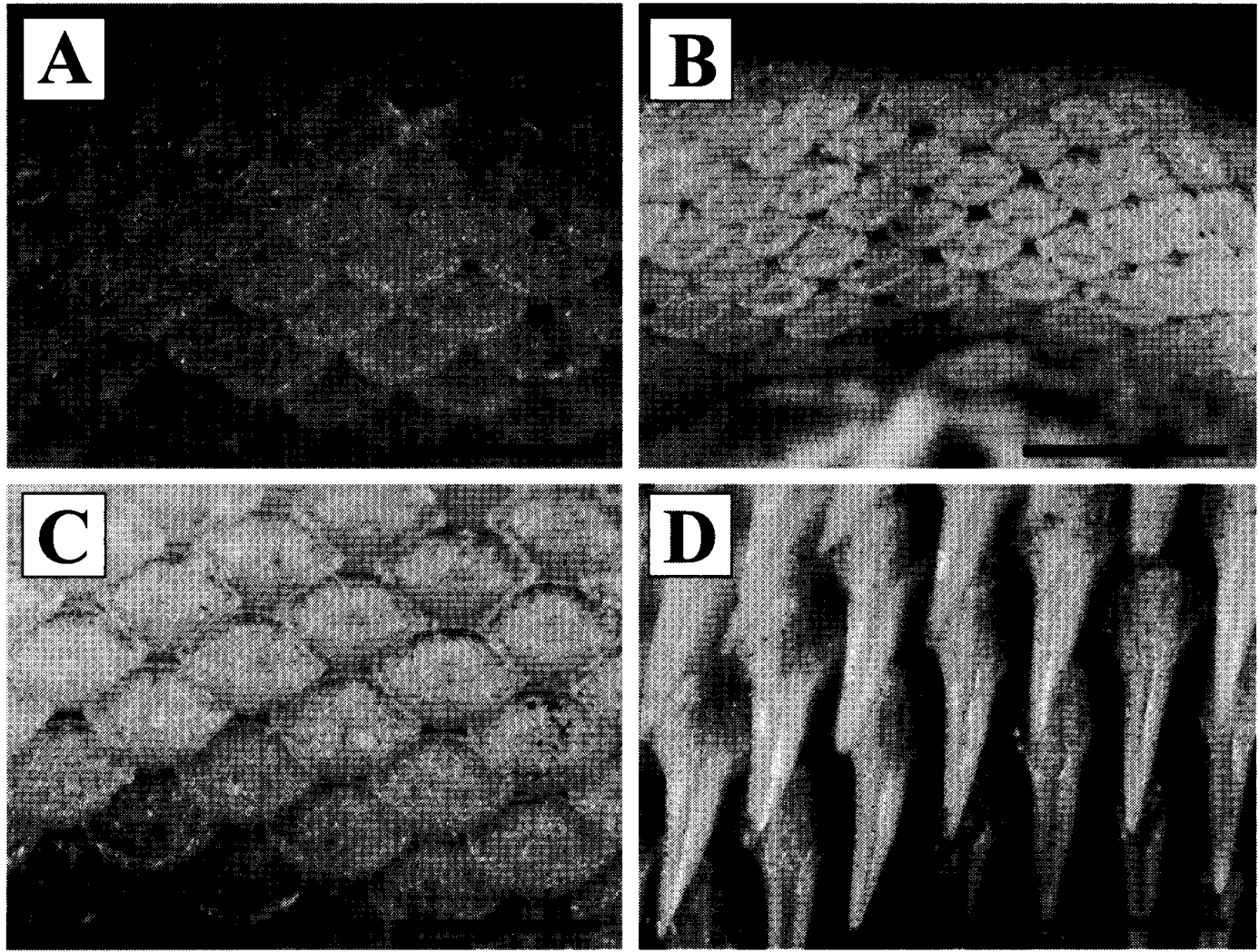

Fig. 3. Light microscope photographs of lower jaw teeth of Dasyatis laevigata. A, Immature female, $208 \mathrm{~mm} \mathrm{DW}$; B, immature male, $120 \mathrm{~mm} \mathrm{DW}$; , mature female, $327 \mathrm{~mm} \mathrm{DW}$; , mature male, $261.5 \mathrm{~mm}$ DW. Scale bars: $1 \mathrm{~mm}$.

in syntype (10.2\% of tail length in 1 of other 18 specimens). Low dorsal tail fold behind posteriormost spine, length $27.8 \%(23.5-53.0 \%)$ of that of ventral tail fold. Ventral tail fold beginning immediately below spine, length $91.1 \%(104.9-155.6 \%)$ of VHL. Preventral tail fold length $130.1 \%(126.9-134.4 \%)$ of disc length. No dorsal or caudal fin.

Pelvic girdle (Fig. 4A, B) thick, anteriorly arched; 2-3 obturator foramina on iliac region; iliac processes moderately long, stout, recurved inwardly; prepelvic processes reduced, lateral ones short, stout, projecting anterolaterally.

Claspers of mature males short, stout (Fig. 4C), length $23.2-24.8 \%$ of disc length, oval in cross section, robust basally, tapering distally to blunt point; ventral pseudosiphon well developed, about as long as clasper glans; small flap at top of glans; dorsal pseudosiphon absent; dorsal margin of hypopyle comb-like.

Clasper skeleton composed of basal, axial, and terminal groups (Fig. 4D, E). Basal group comprising basipterygium of pelvic fin, two basal segments (B1 and B2), and beta cartilage; B1 relatively short, stout, B2 relatively long, cylindrical, connecting pelvic basipterygium to clasper axial cartilage; beta cartilage located on dorsal surface of posterior part of B1, all of B2, and anterior half or so of axial cartilage. Terminal group of clasper composed of six cartilaginous components: 1) long axial cartilage located below dorsal terminal 2 cartilage, reaching to posterior tip of clasper, slender distally with blunt tip; 2) dorsal marginal cartilage broad, 
A B

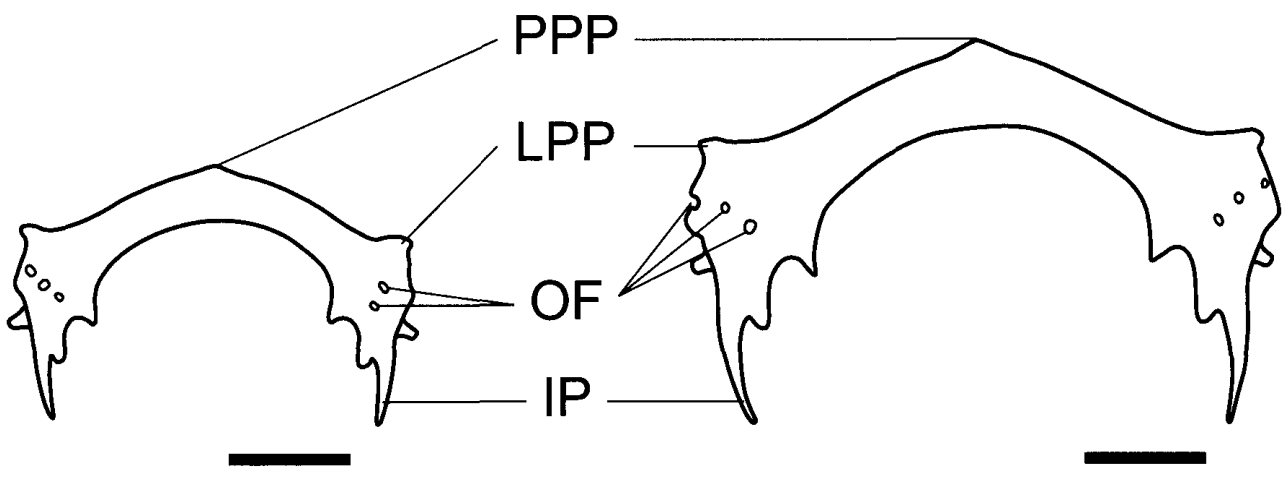

C

D

E
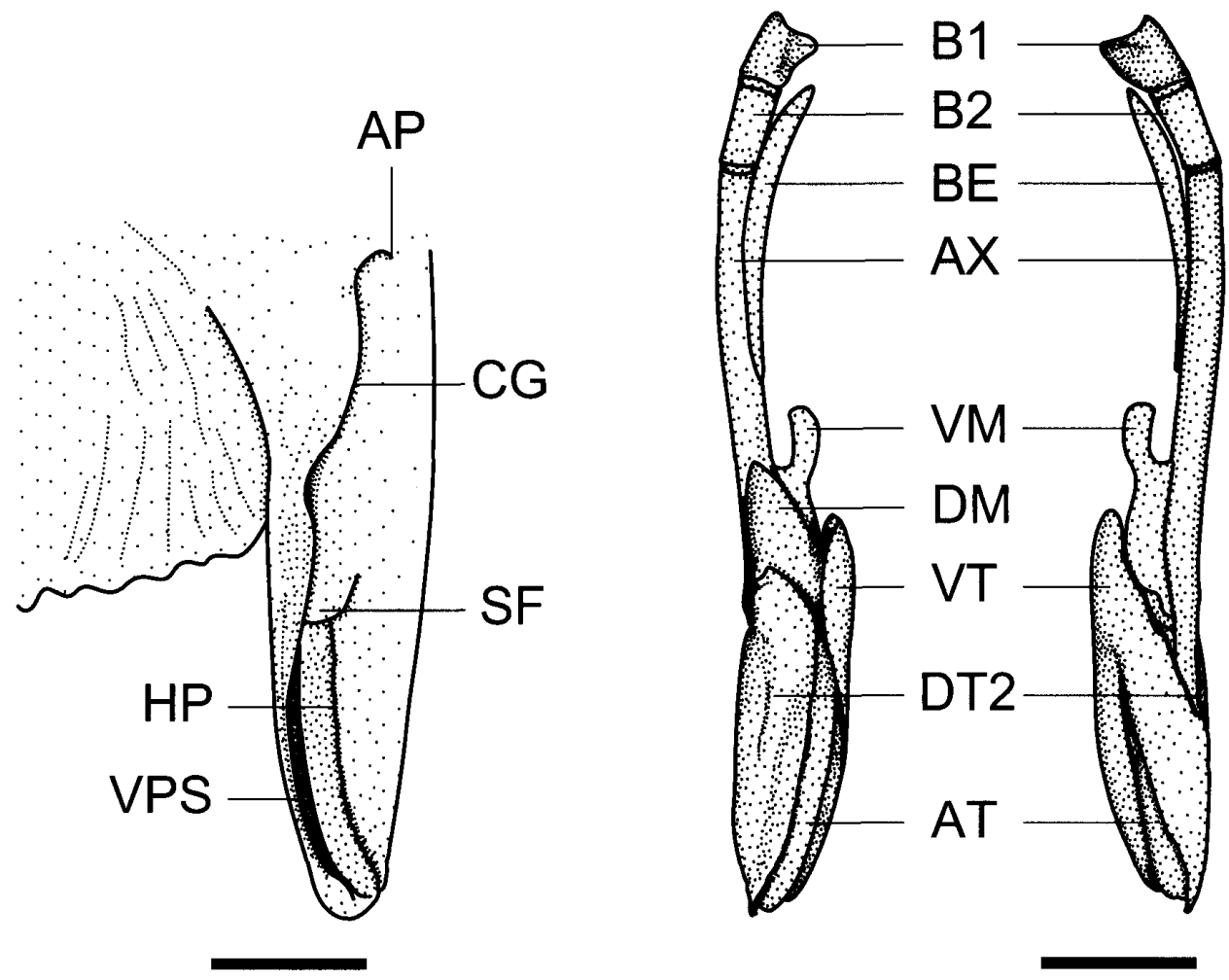

Fig. 4. Pelvic girdle (A,B), left clasper (C), and right clasper skeleton (D,E) of Dasyatis laevigata. A, Dorsal view, $226 \mathrm{~mm}$ DW, mature male (NSMT-P 91821); B, dorsal view, $303 \mathrm{~mm}$ DW, mature female (NSMT-P 91818); C, dorsal view, $286 \mathrm{~mm}$ DW, mature male; D, E, dorsal and ventral views respectively, $286 \mathrm{~mm}$ DW, mature male. Abbreviations: AP, apopyle; AT, accessory terminal cartilage; AX, axial cartilage; B1, B2, basal segments of clasper axis; BE, beta cartilage; CG, clasper groove; DM, dorsal marginal cartilage; DT2, dorsal terminal 2 cartilage; HP, hypopyle; IP, iliac process; LPP, lateral prepelvic process; OF, obturator foramina; PPP, prepelvic process; SF, small flap; VM, ventral marginal cartilage; VPS, ventral pseudosiphon; VT, ventral terminal cartilage. Scale bars: $10 \mathrm{~mm}$ 

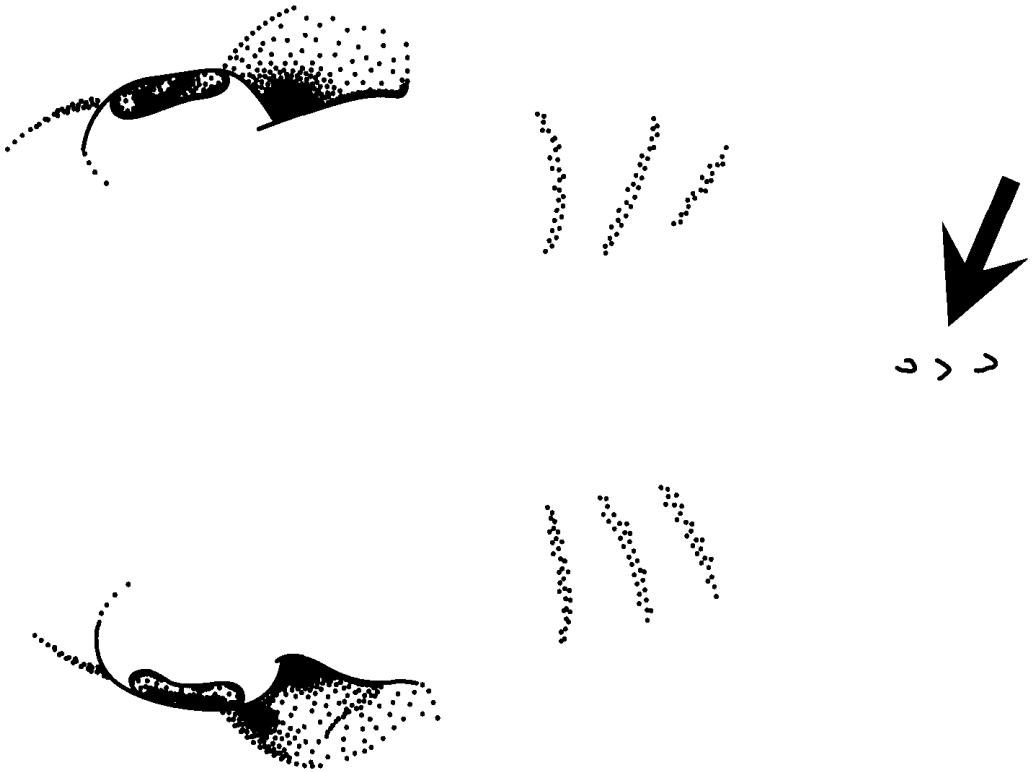

Fig. 5. Dorsal midline thorns in Dasyatis laevigata, $296 \mathrm{~mm}$ DW, mature female (NSMT-P 96557). Scale bar: $10 \mathrm{~mm}$.

triangular, with strongly concave posterior edge and arched cross-section, forming roof of clasper groove; 3 ) dorsal terminal 2 cartilage situated on dorsal aspect of clasper glans, long, oval, shield-like, its mediolateral edge comb-like; 4) ventral marginal cartilage short, narrow, with distinctive spatulate anterior projection, firmly attached to axial cartilage laterally; 5) ventral terminal cartilage large, ovalrectangular, with deep, V-shaped posterior notch; and 6) accessory terminal cartilage long, oval, dome-shaped, its outer edge incurved, broadly overlapping dorsal terminal 2 cartilage and ventral terminal cartilage.

Eighteen non-type specimens with 87-96 prespine separate centra, 98-103 total pectoral radials, 24-27 (5 females) and 19-22 (8 males) pelvic radial cartilages, and 16-18 intestinal spiral valve turns.

Dorsal surface of disc entirely smooth in all specimens, except for single mature female (NSMT-P 96557, $296 \mathrm{~mm} \mathrm{DW}$ ) with row of 3 flattened, posteriorly-pointing thorns on nucho-scapular region (Fig. 5). In all specimens, tubercles, thorns, and denticles absent on tail, pelvic fins, claspers, and ventral surface of disc.

Color of syntype. Dorsal surface of disc and pelvic fin light ocher; ventral surface of disc and pelvic fin white with light ocher outer and posterior margins, and irregular spots; dorsal surface of tail, dorsal tail fold, and ventral tail fold whitish ocher. Overall appearance pale, probably due to long-term preservation in formalin.

Color when fresh (based on non-type specimens). Dorsal surface of disc and pelvic fin grayish-brown; upper side of eyeball and spiracle with light ocher margins; ventral surface of disc and pelvic fin white with grayish-ocher outer and posterior margins and irregular grayish-ocher spots; dorsal tail fold blackish; dorsal surface of tail grayish-brown; ventral tail fold blackish; ventral surface of tail gray- 
Table 3. Comparsion of original description and syntype and non-type specimens of Dasyatis laevigata.

\begin{tabular}{|c|c|c|c|}
\hline & $\begin{array}{l}\text { Original description } \\
\quad(\text { Chu 1960) }\end{array}$ & $\begin{array}{c}\text { Syntype } \\
154,103-8(4)\end{array}$ & $\begin{array}{l}\text { Non-type } \\
\text { specimens } \\
\text { (included in } \\
\text { the description) }\end{array}$ \\
\hline Disc width/Disc length $(\%)$ & $120-130$ & 123.5 & $111.5-122.9$ \\
\hline Preobital snout length/Disc length (\%) & 22.2 & 20.7 & $19.6-23.7$ \\
\hline Eyeball diameter/Interorbital width (\%) & 66.7 & $37.7 *$ & $31.4-49.1$ \\
\hline $\begin{array}{l}\text { Interorbital width/ } \\
\text { Preobital snout length }(\%)\end{array}$ & 50.0 & $72.0^{*}$ & $54.8-72.3$ \\
\hline Preoral snout length/Mouth width (\%) & $240-270$ & $223.2^{*}$ & $223.1-272.6$ \\
\hline $\begin{array}{l}\text { 5th interbranchial width/ } \\
\text { 3rd gill opening length }(\%)\end{array}$ & 350 & $386.0^{*}$ & $297.7-465.5$ \\
\hline Tail length/Disc length (\%) & $140-180$ & 174.7 & $120.2-199.0$ \\
\hline Ventral tail fold length/Tail length (\%) & 40.0 & 24.9 & $27.7-58.6$ \\
\hline Snout angle & about $60^{\circ}$ & $115^{\circ}$ & $108-120^{\circ}$ \\
\hline Oral papillae & 3 & 3 & $1-4$ \\
\hline Upper jaw teeth & about 40 & - & $34-55$ \\
\hline Dark spots on dorsal surface of disc & present & absent & absent \\
\hline Dorsal tail fold & black & whitish-ocher & blackish \\
\hline Ventral tail fold & black & whitish-ocher & blackish \\
\hline Dorsal texture of disc in adult & smooth & smooth & smooth \\
\hline Midline thorns on dorsal surface of disc & absent & absent & $0-3$ \\
\hline Tubercles before spine & absent & absent & absent \\
\hline Posterior tail texture & smooth & smooth & smooth \\
\hline
\end{tabular}

* Measurements from photo.

ish-ocher; distal one-third of tail blackish.

Color in formalin. Similar to that of fresh specimens, except dorsal surface of disc brown; ventral surface whitish with dark outer and posterior margins.

Distribution and habitat. Known from the Yellow Sea and East China Sea off China (Zhu and Meng 2001), Taiwan (Chen and Joung 1993), and Japan, including the Goto Sea (Goto-Nada), Ariake Sea, and Tachibana Bay in Nagasaki Pref., and the Amakusa Sea (Amakusa-Nada) in Kumamoto Pref. (Yamada and Irie 1989; Furumitsu et al. 2006; Furumitsu 2009) (Fig. 6).

Dasyatis laevigata has been recorded inshore and to depths of $60 \mathrm{~m}$ on sandy and muddy bottoms. Juveniles commonly occur in estuaries and shallow coastal waters in summer, but inhabit deeper coastal areas during winter. The species is caught as a bycatch in most fisheries operating in shallow waters off western Kyushu, Japan.

Remarks. Chu (1960) originally described $D$. laevigata based on six syntypes but did not state the repository of those specimens. A search lasting more than seven years was successful in locating only one syntype (154, 103-8 (4)), at the East China Sea Fisheries Research Institute of the Chinese Academy of Fishery Sciences, Shanghai. We were able to examine the syntype at the Institute in April 2006. At the time of writing, however, that specimen, too, has also gone missing (Mr. Anglv Shen, pers. comm., 15 December 2009).

Eight proportional measurements, plus snout angle and two counts, were in- 


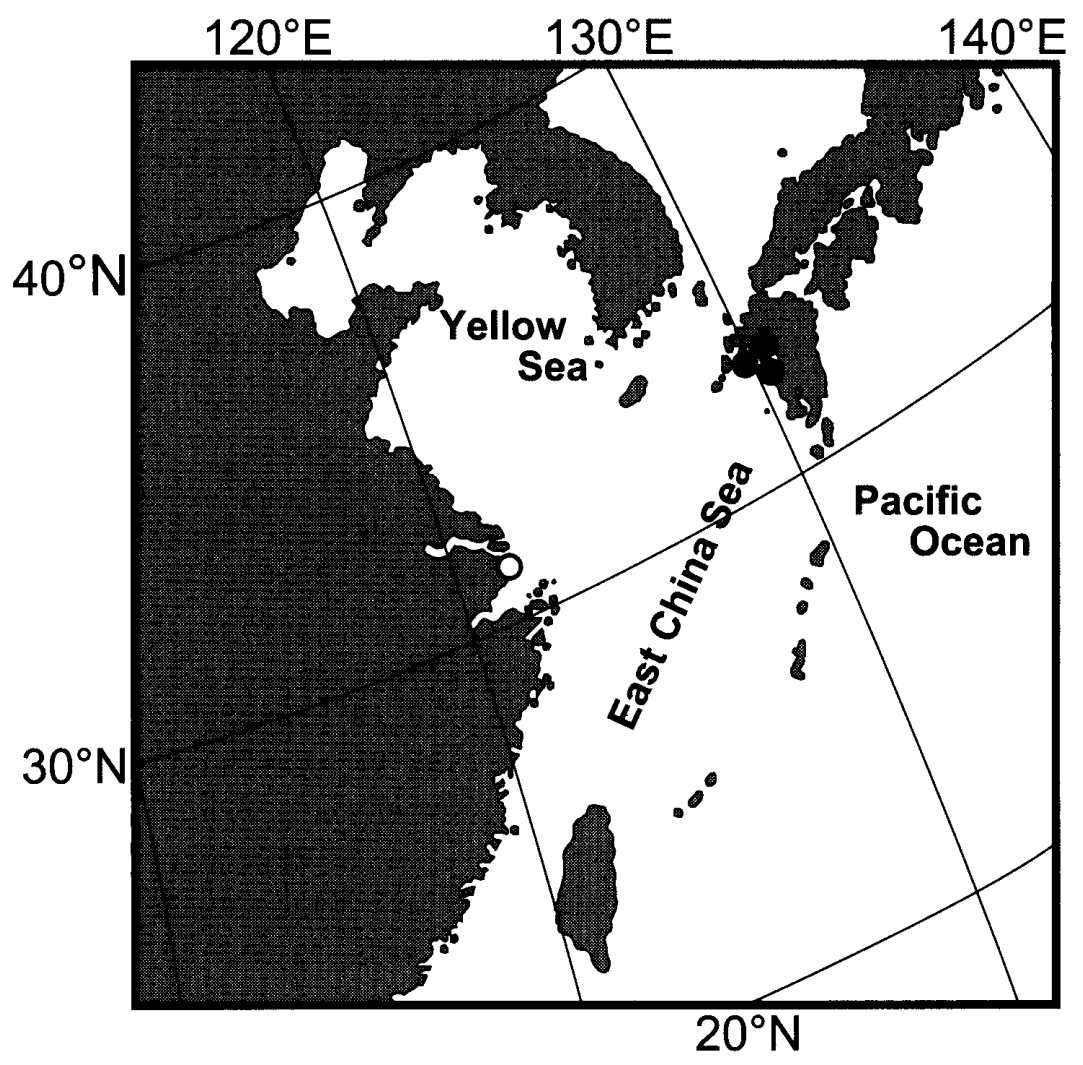

Fig. 6. Collection localities of Dasyatis laevigata. Open circle, syntype (154,103-8 (4)); solid circles, NSMT-P 91808-91814, 91816-91824, 93294, and 96557.

cluded in the original description. Although some differences between the original description and the present data were found (Table 3), the latter correspond well with the measurements of the syntype (154,103-8 (4)) obtained earlier in this study. The measurement methods employed by Chu (1960) were not described, and it is possible that differences in methodology are responsible for the above differences. Variations in the upper tooth rows and oral papillae have been observed, the numbers of the former being about 40 according to Chu (1960), and 34-49 here. The number of oral papillae was three in each of the six specimens of D. laevigata described by Chu (1960), compared with the marked variation (1-8, generally 3 ) observed in this study. Such variation in tooth row number has been reported previously in Dasyatidae (e.g., Nishida and Nakaya 1988a, b). On the other hand, oral papilla numbers are often conservative between individuals and can be used as a diagnostic taxonomic character in some species of Dasyatis. Still, Nishida and Nakaya (1990) observed considerable variation in oral papillae counts in D. akajei. Although the numbers of tooth rows and oral papillae given by Chu (1960) coincided completely with the ranges obtained in the present study, marked variations among individuals in both counts show that neither is suitable as a diagnostic taxonomic character of $D$. laevigata. Size at sexual maturity was smaller in $D$. laevigata than in any other rhomboid-shaped dasyatid species (Furumitsu 2009). A male specimen of $429 \mathrm{~mm}$ total length (converted to $218 \mathrm{~mm} \mathrm{DW}$ ) shown in Chu (1960) had already reached maturity, judging by the appearance of the clasper in his fig. 
162, a situation that supports the identification of the present specimens as D. laevigata. The ventral and dorsal tail folds were described as black in the original description but were whitish-ocher in the syntype $(154,103-8(4))$ that we examined. Since the syntype had been fixed and preserved in formalin for a long time, some coloration may have been lost. The original description indicated that irregular dark spots occurred on the dorsal surface of the disc, but no such spots were shown in the accompanying sketches (figs 160, 162) in Chu (1960). Neither could they be found during our investigations of the syntype (154, 103-8 (4)) and other specimens. It is possible that the spots described by Chu (1960) were simply short-term manifestations resulting from the poor condition of the specimens. Chu (1960) described the dorsal surface of the disc as smooth in all six syntypes (310-630 mm TL), which included mature specimens. In the non-type specimens examined here, while no thorns were observed in immature specimens $(n=200,95-312 \mathrm{~mm} \mathrm{DW})$, several $(13.8 \%)$ sub-adult and mature specimens $(n=282,203-389 \mathrm{~mm} \mathrm{DW})$ had a row of one to nine midline thorns on the dorsal surface of the disc. No differences were found in the 12S rRNA, COI, or cytochrome $b$ regions of mitochondrial DNA between specimens with and without thorns (Yamaguchi and Furumitsu unpublished data); therefore, the occurrence of thorns on the dorsal surface of the disc merely represents intraspecific variation and may have some relationship with growth.

Sexual dimorphism is apparent in the pelvic radial counts (Table 2), possibly resulting from modification of the pelvic cartilage to form clasper elements in males. Sexual dimorphism was also observed in the dentition of males and females. We observed male $D$. laevigata biting at the pectoral fins of females during the mating season, and similar mating behavior is widely known in dasyatids (e.g., Taniuchi and Shimizu 1993; Kajiura et al. 2000; Chapman et al. 2003). Sexual dimorphism was also apparent in size at maturity, with a size difference of approximately $70 \mathrm{~mm}$ in DW between the sexes. A similar trend has been reported in many dasyatids (e.g., Snelson et al. 1989; Capapé 1993; Taniuchi and Shimizu 1993; Villavicencio Garayzar et al. 1994; Capapé and Zaouali 1995).

Nishida and Nakaya (1990) recognized 17 species of Dasyatis from the Northwestern Pacific, including two unnamed species, although three of these have subsequently been placed in Neotrygon, Pastinachus, and Pteroplatytrygon by Last and Stevens (2009). Of the remainder, D. akajei, D. izuensis Nishida and Nakaya, 1988, D. navarrae (Steindachner, 1892), D. sinensis (Steindachner, 1892), D. ushiei Jordan and Hubbs, 1925, and D. sp. 2, all having a rhomboid-shaped disc and a dorsal tail fold, and a dorsal disc surface without white spots, are compared with $D$. laevigata in Table 4 . The latter clearly differs from these congeners by a unique combination of characters.

Biological data. Dasyatis laevigata is a relatively small marine dasyatid, reaching at least $290 \mathrm{~mm}$ DW in males and $369 \mathrm{~mm} \mathrm{DW}$ in females. Clasper outer length ranged from 2.5 to $14.7 \%$ of DW in immature and sub-adult males. The claspers elongated rapidly from $210 \mathrm{~mm}$ DW, but at a decreasing rate as males attained maturity. All males larger than $240 \mathrm{~mm}$ DW were sexually mature (Fig. 7). Uterus weight ranged from 0.01 to $2.60 \mathrm{~g}$ in immature and sub-adult females, increasing rapidly from ca. $300 \mathrm{~mm}$ DW. All females larger than $310 \mathrm{~mm}$ DW were sexually mature (Fig. 8), maturity generally being attained at ca. $300 \mathrm{~mm} \mathrm{DW}$. Although ovaries and uteri were found on both sides in all examined specimens, only those on the left side were functional. Fertilized eggs and embryos were observed 


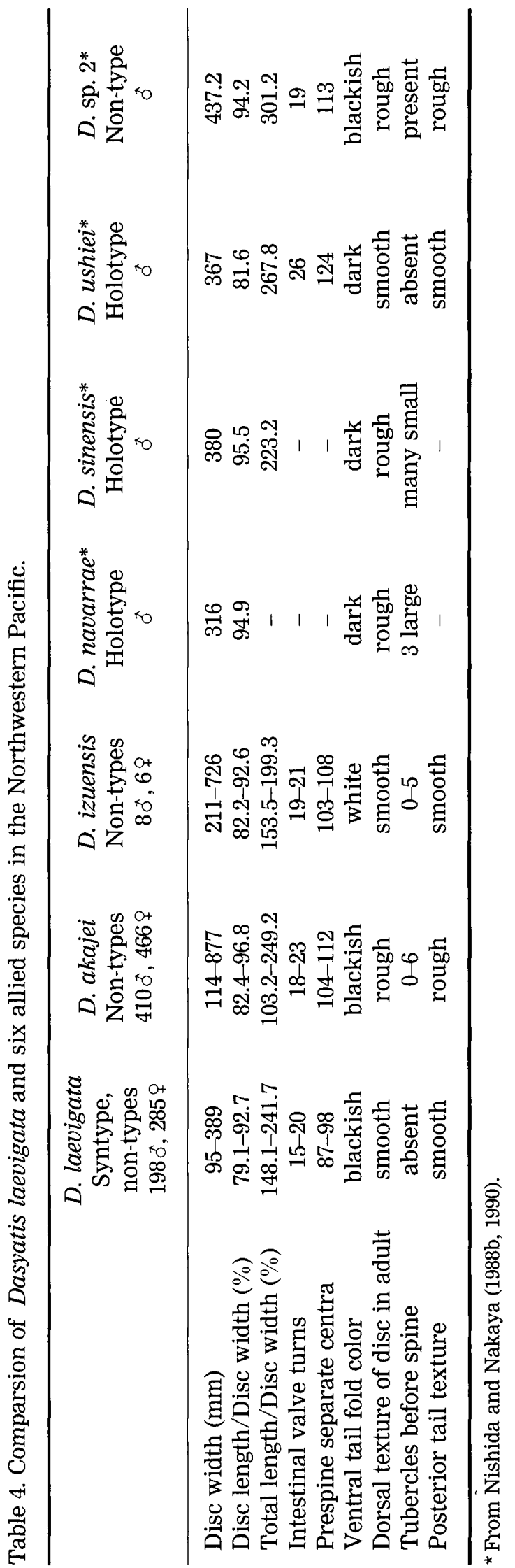




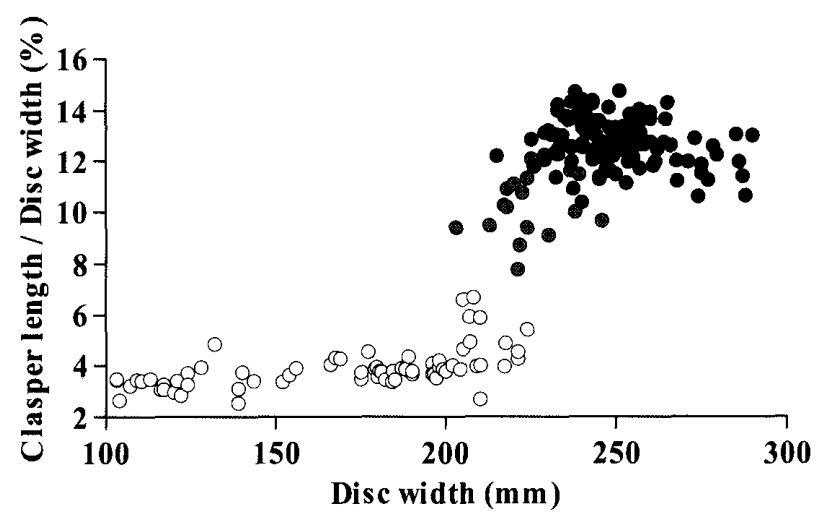

Fig. 7. Relationship between disc width and clasper outer length in 198 males of Dasyatis laevigata. White circles, immature individuals; gray circles, sub-adult individuals; black circles, mature individuals with calcified claspers.

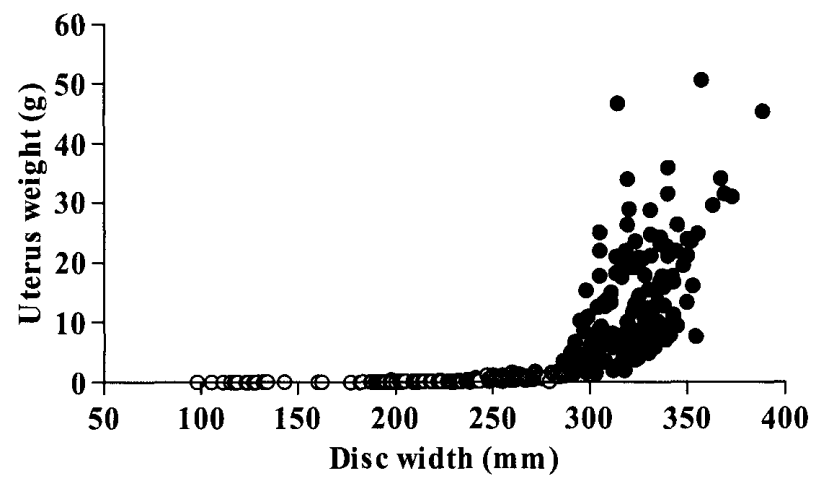

Fig. 8. Relationship between disc width and uterus weight in 272 females of Dasyatis laevigata. White circles, immature individuals; gray circles, sub-adult individuals; black circles, mature individuals.

in the uteri of specimens larger than $290 \mathrm{~mm}$ DW during the breeding season.

\section{Acknowledgments}

We thank S. Yoshida (Shimabara Fishermen's Cooperative Association) and T. Jinkawa (Saga Prefecture Fishery Cooperative Federation) for their help in collecting specimens. We also thank Y.-J. Zheng (East China Sea Fisheries Research Institute, Chinese Academy of Fishery Sciences), W.-Q. Tang (Shanghai Ocean University), and Z.-R. Song (Jimei University) for their assistance during visits by the authors and access to the collections in their care. S. Kimura (Mie University), N. Yagishita and G. Kume (Nagasaki University), and K. Nishida (Osaka Waterfront Development Company Limited) kindly provided helpful advice. We are grateful to G. Shinohara (National Museum of Nature and Science) for registering specimens there. Constructive comments on the manuscript from Graham Hardy were much appreciated. This study was partly supported by a Grant-in-Aid (20580205) from the Ministry of Education, Culture, Sports, Science and Technology of Japan. 


\section{References}

Aonuma, Y. and Yoshino, T. 2000. Dasyatidae. Pp. 177-182. In: Nakabo, T. (Ed.) Fishes of Japan with Pictorial Keys to the Species, Second Edition. Tokai University Press, Tokyo. [In Japanese]

Braccini, J. M. and Chiaramonte, G. E. 2002. Reproductive biology of Psammobatis extenta. Journal of Fish Biology 61: 272-288.

Capapé, C. 1993. New data on the reproductive biology of the thorny stingray, Dasyatis centroura (Pisces: Dasyatidae) from off the Tunisian coasts. Environmental Biology of Fishes 38: 73-80.

Capapé, C. and Zaouali, J. 1995. Reproductive biology of the marbled stingray, Dasyatis marmorata (Steindachner, 1892) (Pisces: Dasyatidae) in Tunisian waters (Central Mediterranean). Journal of Aquaculture and Aquatic Sciences 7: 108-119.

Chapman, D. D., Corcoran, M. J., Harvey, G. M., Malan, S. and Shivji, M. S. 2003. Mating behavior of southern stingrays, Dasyatis americana (Dasyatidae). Environmental Biology of Fishes 68: 241-245.

Chen, C.-T. and Joung, S. J. 1993. Dasyatidae. Pp. 82-86. In: Shen, S.-C. (Ed.) Fishes of Taiwan. Department of Zoology, National Taiwan University, Taipei. [In Chinese]

Chu, Y.-T. 1960. Zhongguo Ruangu Yuleizhi [The Cartilaginous Fishes of China]. Science Press, Beijing, $\mathrm{x}+225 \mathrm{pp}$. [In Chinese]

Chu, Y.-T., Wu, H.-L. and Wang, Y.-H. 1963. Dasyatidae. Pp. 62-68. In: Chu, Y.-T., Zhang, C.-L. and Cheng, Q.-T. (Eds) The Fishes of East China Sea. Science Press, Beijing. [In Chinese]

Compagno, L. J. V. 2005. Checklist of living Chondrichthyes. Pp. 503-548. In: Hamlett, W. C. (Ed.) Reproductive Biology and Phylogeny of Chondrichthyes. Sharks, Batoids and Chimaeras. Science Publishers, Enfield, New Hampshire, USA.

Compagno, L. J. V. and Roberts, T. R. 1982. Freshwater stingrays (Dasyatidae) of Southeast Asia and New Guinea, with description of a new species of Himantura and reports of unidentified species. Environmental Biology of Fishes 7: 321-339.

Compagno, L. J. V. and Roberts, T. R. 1984. Marine and freshwater stingrays (Dasyatidae) of West Africa, with description of a new species. Proceedings of the California Academy of Sciences 43: 283-300.

Furumitsu, K. 2009. Studies on Taxonomy and Life History of Genus Dasyatis from Eastern Asia. Ph.D. thesis, Nagasaki University, Nagasaki, 190 pp. [In Japanese]

Furumitsu, K., Yamaguchi, A. and Nishida, K. 2006. Taxonomy and biology of the yantai stingray, Dasyatis laevigata. Kaiyo Monthly, Gogai 45: 32-36. [In Japanese]

Gomes, U. L., Rosa, R. S. and Gadig, O. B. F. 2000. Dasyatis macrophthalma sp. n.: a new species of stingray (Chondrichthyes: Dasyatidae) from the southwestern Atlantic. Copeia 2000: 510-515.

Jordan, D. S. and Hubbs, C. L. 1925. Record of fishes obtained by David Starr Jordan in Japan, 1922. Memoirs of the Carnegie Museum 10: 93-346, pls 5-12.

Kajiura, S. M., Sebastian, A. P. and Tricas, T. C. 2000. Dermal bite wounds as indicators of reproductive seasonality and behaviour in the Atlantic stingray, Dasyatis sabina. Environmental Biology of Fishes 58: 23-31.

Last, P. R. and Stevens, J. D. 2009. Family Dasyatidae. Pp. 429-462. In: Last, P. R. and Stevens, J. D. (Eds) Sharks and Rays of Australia, Second Edition. CSIRO Publishing, Hobart.

Last, P. R. and White, W. T. 2008a. Dasyatis parvonigra sp. nov., a new species of stingray (Myliobatoidei: Dasyatidae) from the tropical eastern Indian Ocean. CSIRO Marine and Atmospheric Research Paper 22: 275-282. 
Last, P. R. and White, W. T. 2008b. Resurrection of the genus Neotrygon Castelnau (Myliobatoidei: Dasyatidae) with the description of Neotrygon picta sp. nov., a new species from northern Australia. CSIRO Marine and Atmospheric Research Paper 22: 315-325.

Müller, J. and Henle, J. 1841. Systematische Beschreibung der Plagiostomen. Verlag von Veit und Comp., Berlin, xxii + 200 pp., 60 pls.

Nishida, K. 1990. Phylogeny of the suborder Myliobatidoidei. Memoirs of the Faculty of Fisheries, Hokkaido University 37: 1-108.

Nishida, K. and Nakaya, K. 1988a. A new species of the genus Dasyatis (Elasmobranchii: Dasyatididae) from southern Japan and lectotype designation of $D$. zugei. Japanese Journal of Ichthyology 35: 115-123.

Nishida, K. and Nakaya, K. 1988b. Dasyatis izuensis, a new stingray from the Izu Peninsula, Japan. Japanese Journal of Ichthyology 35: 227-235.

Nishida, K. and Nakaya, K. 1990. Taxonomy of the genus Dasyatis (Elasmobranchii, Dasyatididae) from the North Pacific. Pp. 327-346. In: Pratt Jr., H. L., Gruber, S. H. and Taniuchi, T. (Eds) NOAA Technical Report 90. Elasmobranchs as Living Resources: Advances in the Biology, Ecology, Systematics, and the Status of the Fisheries. United States of America Department of Commerce, Seattle.

Rafinesque, C. S. 1810. Caratteri di Alcuni Nuovi Generi e Nuove Specie di Animali e Piante della Sicilia con Varie Osservazioni sopra i Medisimi. Parts 1-3. Sanfilippo, Palermo, 105 pp., 20 pls.

Snelson, F. F., Williams-Hooper, S. E. and Schmid, T. H. 1989. Biology of the bluntnose stingray, Dasyatis sayi, in Florida coastal lagoons. Bulletin of Marine Science 45: 15-25.

Stehmann, M. 1981. Batoid fishes, technical terms and principal measurements used. Pp. 1-8. In: Fischer, W., Bianchi, G. and Scott, W. B. (Eds) FAO Species Identification Sheets for Fishery Purposes. Eastern Central Atlantic. Fishing Area 34, 47 (in part). Vol. 5. Department of Fisheries and Oceans, Canada, Ottawa.

Taniuchi, T. and Ishihara, H. 1990. Anatomical comparison of claspers of freshwater stingrays (Dasyatidae and Potamotrygonidae). Japanese Journal of Ichthyology 37: 10-16.

Taniuchi, T. and Shimizu, M. 1993. Dental sexual dimorphism and food habits in the stingray Dasyatis akajei from Tokyo Bay, Japan. Bulletin of the Japanese Society of Scientific Fisheries 59: 53-60.

Villavicencio Garayzar, C. J., Hoffmann, C. D. and Melendez, E. M. 1994. Size and reproduction of the ray Dasyatis longus (Pisces: Dasyatidae), in Bahía Almejas, Baja California Sur, Mexico. Revista de Biología Tropical 42: 375-377.

Yamada, U. and Irie, T. 1989. [On the fishes of the East China Sea and the Yellow Sea]. Seikaiku Suisan Kenkyusho News 62: 21-27. [In Japanese]

Zhu, Y. and Meng, Q. 2001. Dasyatidae. Pp. 412-431. In: Zhu, Y. and Meng, Q. (Eds) Fauna Sinica: Cyclostomata, Chondrichthyes. Science Press, Beijin. [In Chinese] 